Kahina Djafri*, Mouloud Challal and Jordi Romeu

\title{
A Compact Dual-Band Planar Monopole Antenna Using Fractal Rings and A Y-Shaped Feeding Transmission Line
}

https://doi.org/10.1515/freq-2018-0097

Received April 17, 2018

\begin{abstract}
This paper presents a novel design approach of a compact dual-band monopole antenna with an overall size of $18.9 \times 13 \times 1.6 \mathrm{~mm}^{3}$. The proposed antenna is composed of a fractal ring shaped patch fed by a Y-shaped transmission line on the top side of the substrate and a second fractal ring along with a U-shaped ground plane on the bottom side. The second fractal ring, identical to the radiating ring, is loaded and a rectangular slot is etched at the top side of the ground plane respectively, to achieve dual-band characteristic and improve the impedance matching. The effect of standard groundplane (SGP) of a laptop computer is incorporated in the design; the antenna is mounted on a SGP in order to investigate its performance. The antenna covers widely the frequency bands of the WLAN $2.4 \mathrm{GHz}(2.2-2.52 \mathrm{GHz})$ and WiMAX $3.5 \mathrm{GHz}(3.32-4.35 \mathrm{GHz})$, and exhibits an omnidirectional radiation pattern in the $\mathrm{H}$-plane and a monopole like radiation pattern in the E-plane. A good agreement between the simulated and measured results indicates that the proposed dual-band antenna design is suitable for WLAN/WiMAX applications.
\end{abstract}

Keywords: fractal ring, Y-shaped feeding line, miniaturization, dual-band, electromagnetic (EM) coupling, WLAN, WiMAX, standard ground-plane (SGP)

\footnotetext{
*Corresponding author: Kahina Djafri, Signals and Systems Laboratory, Institute of Electrical and Electronic Engineering, University M'Hamed BOUGARA of Boumerdes, Boumerdes, Algeria, E-mail: k.djafri@univ-boumerdes.dz https://orcid.org/0000-0002-0715-442X

Mouloud Challal, Signals and Systems Laboratory, Institute of Electrical and Electronic Engineering, University M'Hamed BOUGARA of Boumerdes, Boumerdes, Algeria,

E-mail: mchallal@univ-boumerdes.dz

https://orcid.org/0000-0002-6745-2904

Jordi Romeu, CommSensLab, Universitat Politècnica de Catalunya, Barcelona, Spain, E-mail: romeu@tsc.upc.edu
}

\section{Introduction}

With the rapid development of modern wireless communication systems, the demand for antennas with compact size, lightweight, multi-band operation and high efficiency, capable to be embedded in diverse devices, has increased considerably. To achieve that, many research works have been conducted to design compact antennas which can operate in multiple bands and hence cover different communication applications [1, 2]. Therefore, numerous antenna size reduction techniques have been reported and investigated in the literature. These include loading the patch with a shorting post [3], introducing of defected microstrip structure (DMS) [4], using defected ground structure (DGS) [5, 6], Asymmetric Coplanar Strip (ACS) feeding [7] and metamaterial structure [8]. However, the resulted structures have demonstrated a relatively large size for the requirement of nowadays wireless applications.

Using fractal approach to design convoluted geometries that result in reduced size antennas is very attractive solution to achieve compact size with multiband and broadband performances [9-12]. This is due to two common properties of fractal geometries: self-similarity and space filling [13, 14]. Self-similarity generates multiband and broadband behavior while space filling leads to antenna size reduction. Since fractal patterns can add more electrical length in less volume and area. Consequently, they are considered as powerful design technique of compact multiband antennas. In [14], an ultra-wideband (UWB) fractal antenna in monopole configuration has been proposed. Wide band behavior and miniaturization have been achieved using concentric heptagonal array structure. A Sierpinski carpet fractal antenna printed on a flexible substrate that operates in universal mobile telecommunication system (UMTS) band has been presented in [15]. The proposed structure was compact with overall dimensions of $70 \times 31 \times 0.075 \mathrm{~mm}^{3}$ and the obtained results have shown that the proposed fractal antenna is more tolerant to folding than the conventional patch and exhibits relatively stable radiation patterns even when folded in complex manners. A design 
approach for dual-band coplanar waveguide (CPW)-fed pentagonal ring fractal patch antenna which operates at two wide resonant frequency bands, covering worldwide interoperability for microwave access (WiMAX: 3.3$3.69 \mathrm{GHz}$ ) and wireless local area networks (WLAN: $5.150-5.825 \mathrm{GHz}$ ), simultaneously, has been proposed in [16].

In this paper, a novel compact dual-band monopole antenna with omnidirectional radiation pattern is designed, fabricated and tested. By an appropriate combination of two coupled first-order hexagonal fractal rings, one printed on the top side of the substrate whereas the second one embedded in the ground plane, along with Y-shaped feeding line, a dual-band operation as well as size reduction are achieved. The fractal rings perimeter and the dimensions of the feeding line are varied to obtain the desired resonant frequency bands which widely cover the bands allocated to WLAN at $2.4 \mathrm{GHz}$ and WiMAX at $3.5 \mathrm{GHz}$, simultaneously. Furthermore, an investigation is performed in order to study the effects of mounting the proposed antenna on the side of a standard ground-plane (SGP) of laptop computer, on the antenna performance. The design and simulation were carried out using CST microwave studio®. The simulated and measured return losses and radiation patterns of the proposed antenna are presented and discussed. The measured antenna provides satisfactory results in terms of good reflection coefficient and radiation patterns, demonstrating that it is well-suited for WLAN/WiMAX applications.

\section{Antenna structure and design procedure}

Figure 1 shows the geometry of the proposed dual-band monopole antenna along with its details. The proposed structure consists of two first-iterative hexagonal fractal rings, a Y-shaped transmission line and a U-shaped ground plane. On the top side of the substrate, is a fractal radiating ring fed with a Y-shaped transmission line while in the other side of the substrate is a second fractal ring, electromagnetically coupled with the first one, and a U-shaped ground plane. The process of generation of the fractal ring is illustrated in Figure1 (c). The proposed structure is designed on a $1.6 \mathrm{~mm}$ thick FR-4 substrate with permittivity and loss tangent of 4.3 and 0.017 , respectively. The antenna dimensions are optimized by varying one variable at a time and keeping the others as constants. The proposed design dimensions are listed in Table 1.

The design process involves three different evolution stages as depicted in Figure 2. Initially, a simple hexagonal ring fed with a Y-shaped transmission line along with a U-shaped ground plane is designed, denoted as Antenna 1. To downsize the antenna dimensions, instead of using a simple hexagonal shape, a first-iterative fractal hexagonal ring is introduced to derive Antenna 2. Moreover, to achieve dual-band operation and to further reduce the antenna dimensions, a second fractal ring, with same dimensions as the radiating ring, is embedded in the ground plane to design the proposed antenna, denoted as Antenna 3.

\section{Results and discussion}

Figure 3 shows a comparison of the simulated reflection coefficients of Antenna 1, Antenna 2 and Antenna 3. It can be seen from the results that Antenna 1 resonates at 4.19 GHz while Antenna 2 resonates at $3.03 \mathrm{GHz}$. Thus, it can be concluded that by introducing the fractal radiating ring a shift of the resonant frequency from 4.19 to $3.03 \mathrm{GHz}$ is observed. Accordingly, an antenna size reduction is achieved. Furthermore, by loading Antenna 2 with a second fractal ring in the ground plane (Antenna 3), an electromagnetic coupling between the two fractal rings is created leading to dual-band operation $(2.45 / 3.5 \mathrm{GHz})$ and further reduction in antenna size in terms of the first resonant frequency value.

To further investigate the operating mechanism of the proposed antenna namely Antenna 3, the current distributions are simulated at the two resonant frequencies of 2.45 and $3.48 \mathrm{GHz}$ as depicted in Figure 4. It can be observed that, at the first resonant frequency, the current is mostly concentrated on the two opposite sides of the fractal radiating ring as well as at the two opposite sides of the parasitic fractal ring embedded in the ground plane. This confirms the fact that this first band is the result of the EM coupling between the two fractal rings. Consequently, the first resonant frequency can be controlled by changing the circumference of the fractal rings. Concerning the current at the second resonant frequency, it is mainly concentrated in the Y-shaped feed line as well as in the two fractal rings. Therefore, this second resonance can be tuned by changing the dimensions of the feeding line and the perimeter of the radiating fractal rings. 


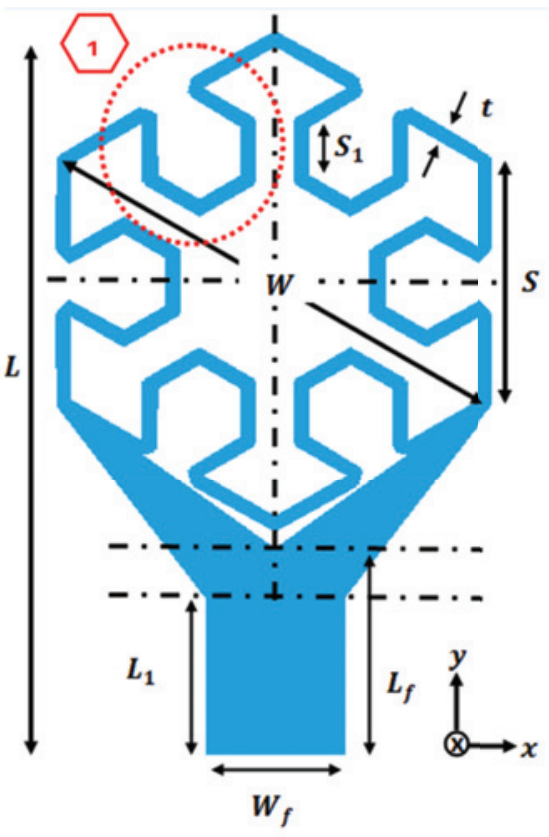

(a)

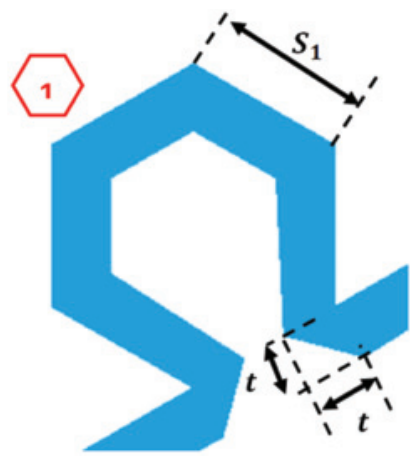

(c)
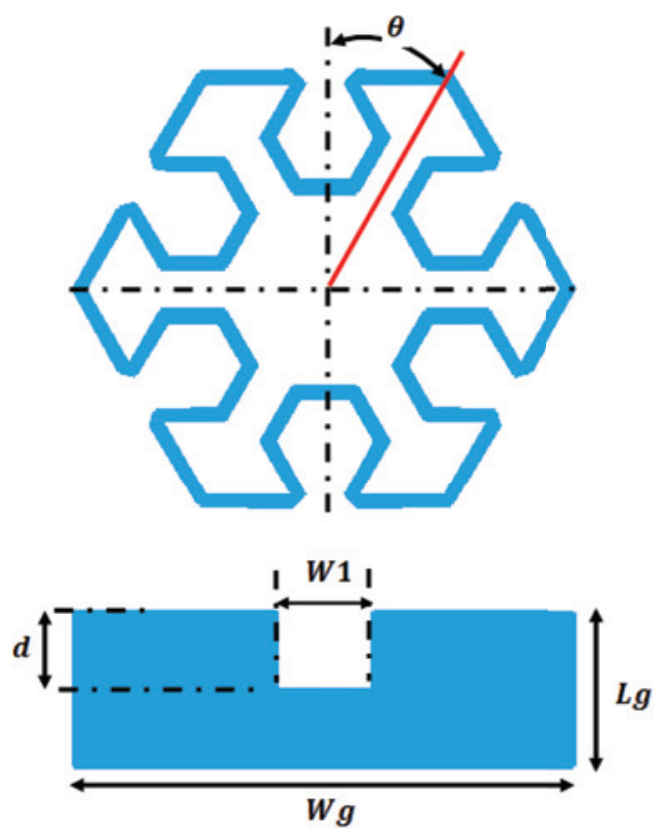

(b)

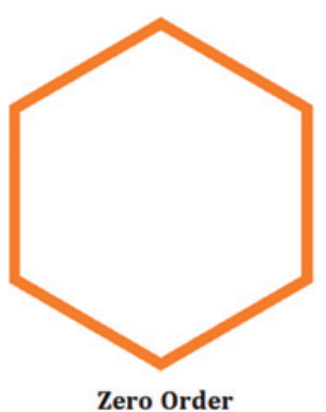

Zero Order

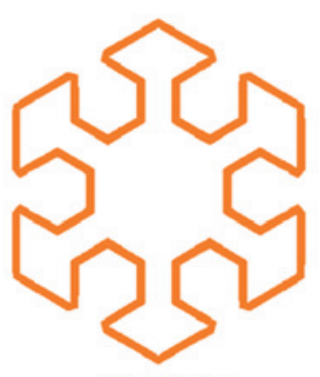

First Order

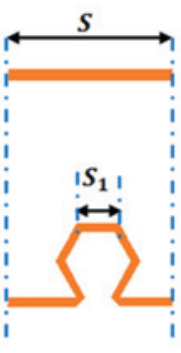

Generator (d)

Figure 1: Geometry of the proposed dual-band antenna, (a) Top view, (b) Bottom view, (c) Detail of the hexagonal fractal ring and, (c) The generation procedure of the hexagonal fractal ring.

Table 1: Geometrical dimensions of the proposed antenna.

\begin{tabular}{|c|c|c|c|c|c|c|c|c|c|c|c|c|c|}
\hline Parameter & $\mathbf{L}$ & L1 & Lf & Wf & W1 & S1 & S & w & $\theta$ & Lg & Wg & d & $t$ \\
\hline Value (mm) & 18.9 & 5.2 & 4.1 & 3.5 & 6.2 & 1.65 & 6.5 & 13 & $30^{\circ}$ & 4 & 13 & 2 & 0.3 \\
\hline
\end{tabular}

Figure 5(a) shows the results obtained through simulation of the return loss characteristic according to the change of S1 while all other parameters are kept constants. As the value of S1 increases, both resonant frequencies shift toward the lower frequencies. Thus, by increasing S1, the electric current gets lengthened on the fractal radiating rings which causes the resonant frequency to decrease. It is clear that the two resonances are centered at the desired bands, $2.45 \mathrm{GHz}$ and $3.5 \mathrm{GHz}$, with a good impedance matching when S1 equals to $1.65 \mathrm{~mm}$.

Figure 5(b) shows the effect of varying the feed line width (Wf) on the return loss. It is found that by increasing the width Wf, the lower cut off frequency 


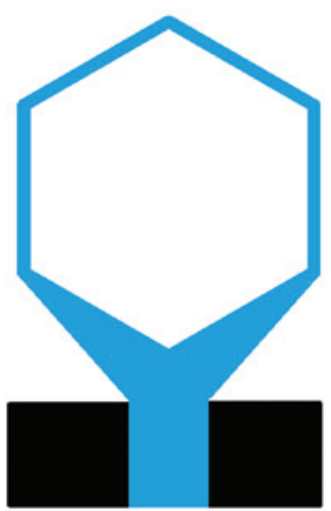

Antenna 1

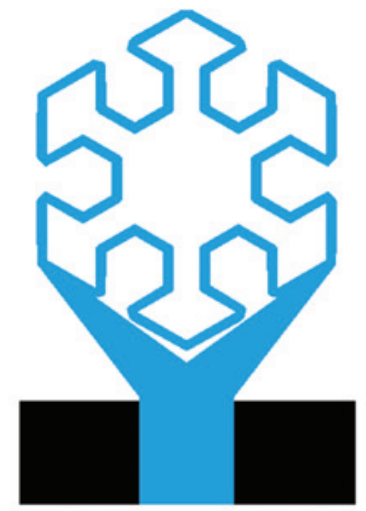

Antenna 2

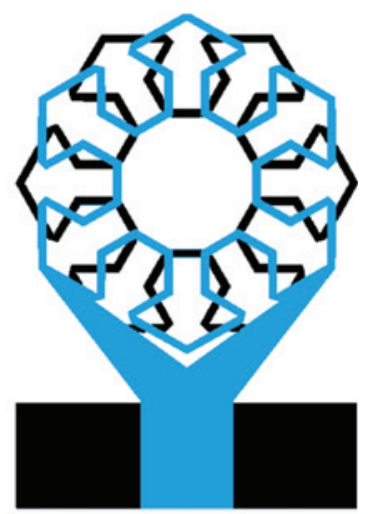

Proposed Antenna

Figure 2: Geometry of different antennas involved in the design development.

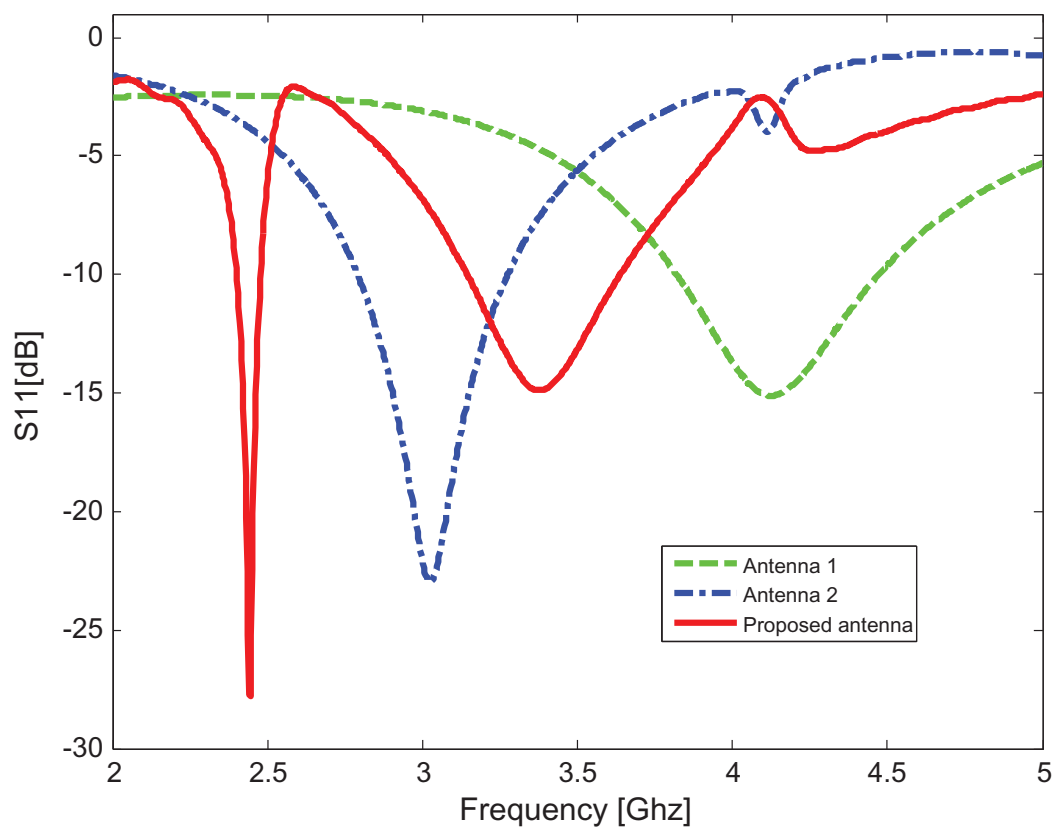

Figure 3: Return losses versus frequency for different antenna structures.

of the second band deceases with improvement of the impedance matching for the second band. For Wf equals to $3.5 \mathrm{~mm}$, good impedance matching at both resonant frequencies is obtained.

The effect of varying the fractal rings width $(t)$ on the return loss is shown in Figure 5(c). It is observed that by increasing the parameter $t$, the two resonant frequencies shift to the higher frequencies. This is due to the decrease of the fractal ring inductance. For t equals to $0.3 \mathrm{~mm}$, the two resonant frequencies are tuned to the desired bands.

The effect of varying the open slot depth etched in the ground plane (d) on the return loss is shown in Figure 5(d). It can be seen that better impedance matching is achieved for the second band, without affecting the first one, by changing the parameter $\mathrm{d}$. This good impedance matching is obtained for d equals to $2 \mathrm{~mm}$.

Figure 5(e) shows the effect of varying the ground plane length $(\mathrm{Lg})$ on the return loss. It is noticed from the results that the lower cut off frequency of the second resonant frequency shifts towards lower frequencies as the value of Lg decreases. Consequently, the second band broadens and the impedance matching improves. It can be concluded that for Lg equals $4 \mathrm{~mm}$ optimum results are obtained in terms of bandwidth and impedance matching for the second band.

Figure 5(f) illustrates the effect of changing the angle $\theta$ on the return loss. By increasing the value of the angle 

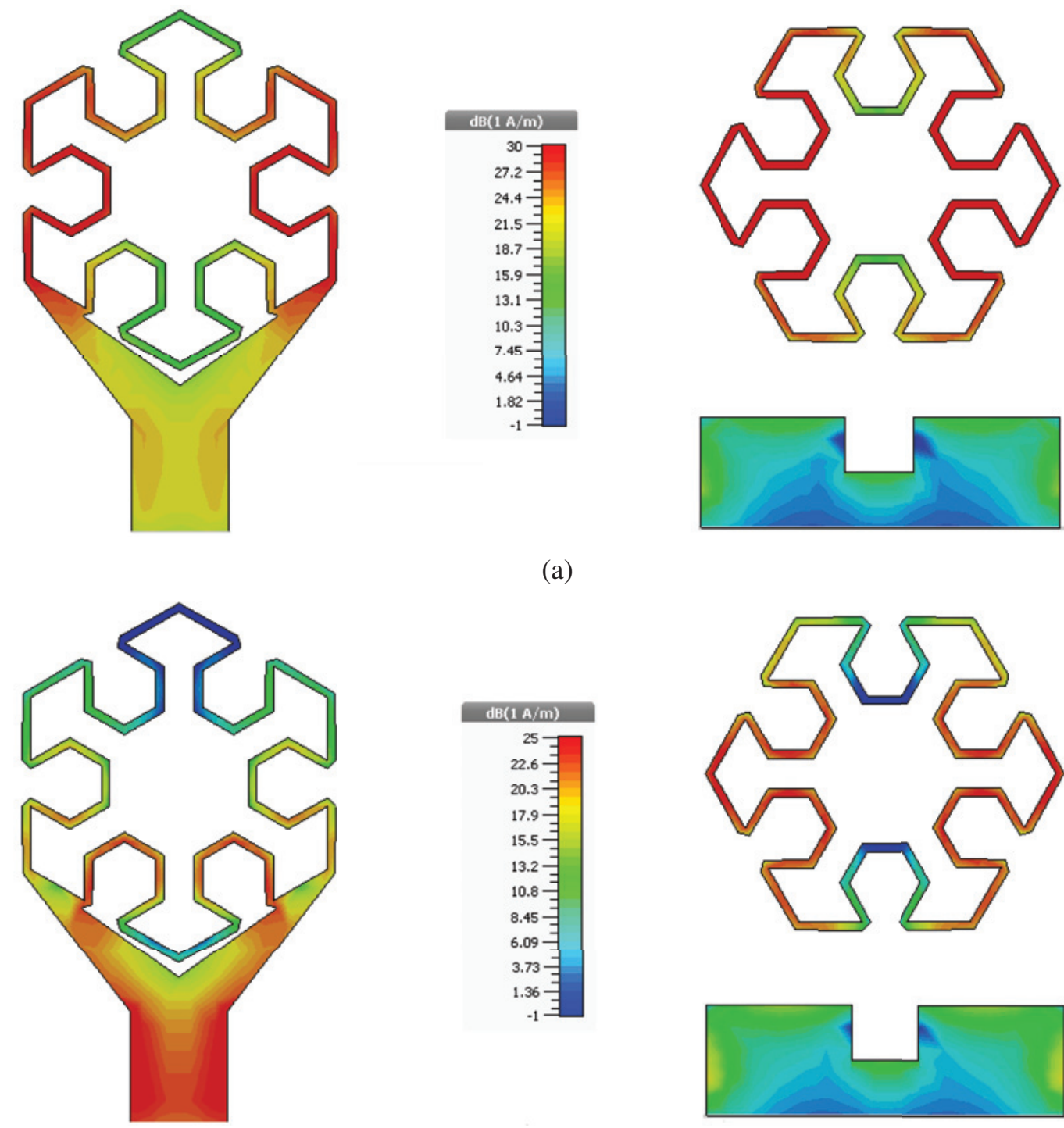

(a)
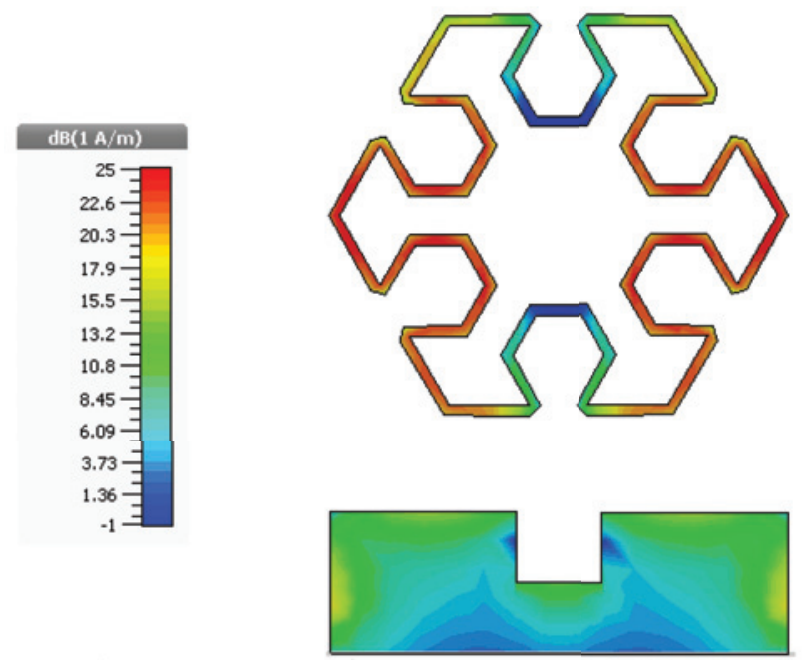

(b)

Figure 4: Current distributions for the proposed antenna (a) at 2.45 and, (b) at $3.5 \mathrm{GHz}$.

$\theta$, the first resonant frequency shifts to the lower frequencies while the second one kept roughly constant. This shift is resulted from the change in the EM coupling between the fractal radiating rings. It is clear that the first operating band is centered at around $2.45 \mathrm{GHz}$ for $\theta$ of $30^{\circ}$.

\section{Fabrication and measurement}

To validate the technical proposal, the proposed dualband monopole antenna was fabricated and tested. Figure 6 shows the photograph of the fabricated prototype of the proposed dual-band antenna. The fabricated structure performances were measured using a Rohde \& Schwarz R\&S®ZNB vector network analyzer (VNA) operating in the frequency band $100 \mathrm{KHz}-20 \mathrm{GHz}$. The measured and simulated return losses are depicted in Figure 7. It can be observed that the measured and simulated results are in good agreement with measured 10-dB impedance bandwidths of $300 \mathrm{MHz}(2220-2520 \mathrm{MHz}, 12.6 \%)$ and $1030 \mathrm{MHz}(3320-4350 \mathrm{MHz}, 26.8 \%)$ covering the $2.4 \mathrm{GHz}$ WLAN and $3.5 \mathrm{GHz}$ WiMax bands, respectively. The slight deviation in the measured results is basically due to the manufacturing tolerances, the uncertainty on the thickness and dielectric relative constant of the substrate added to the SMA connectors quality. 


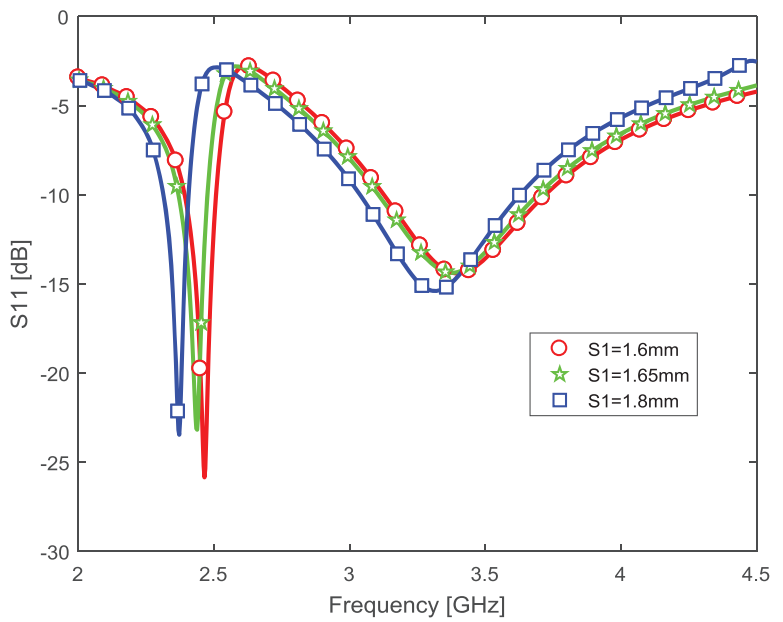

(a)

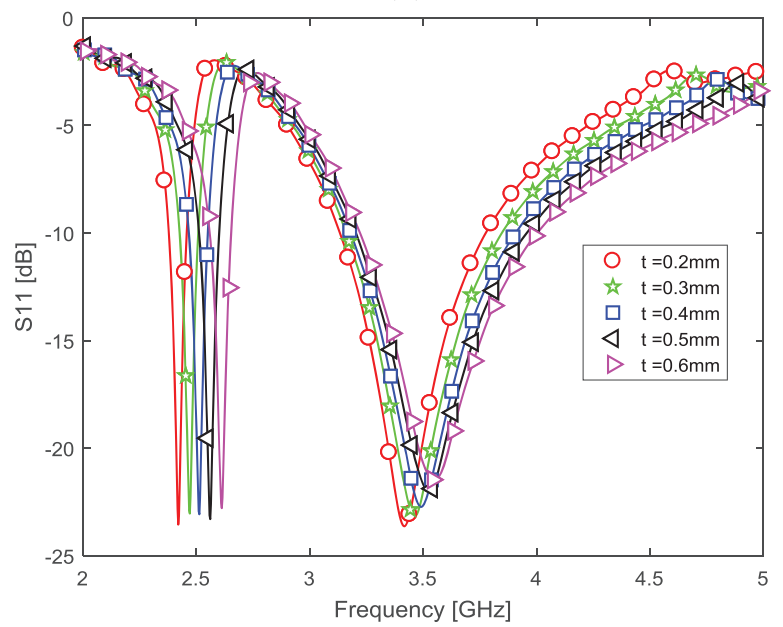

(c)

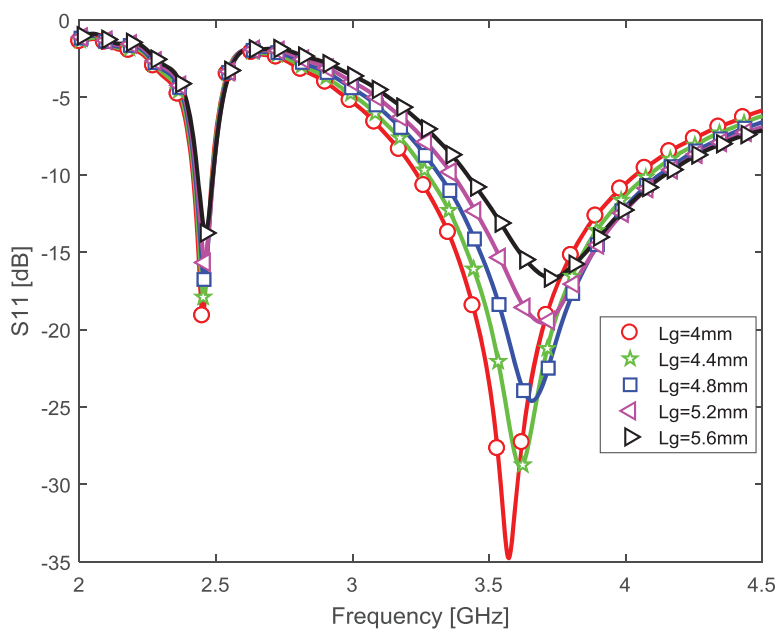

(e)

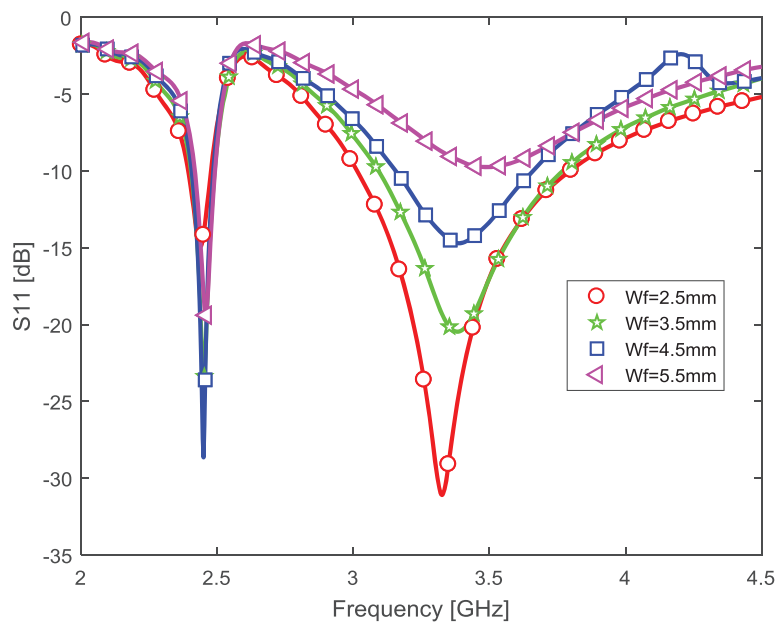

(b)

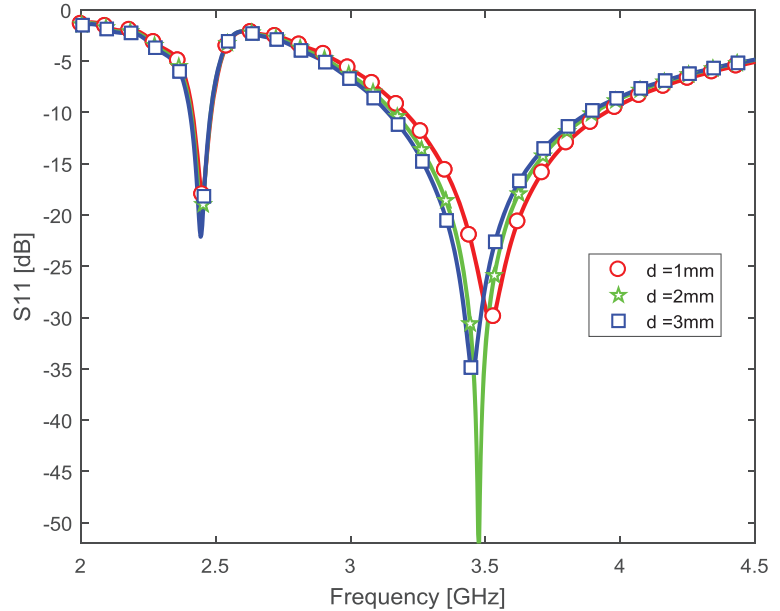

(d)

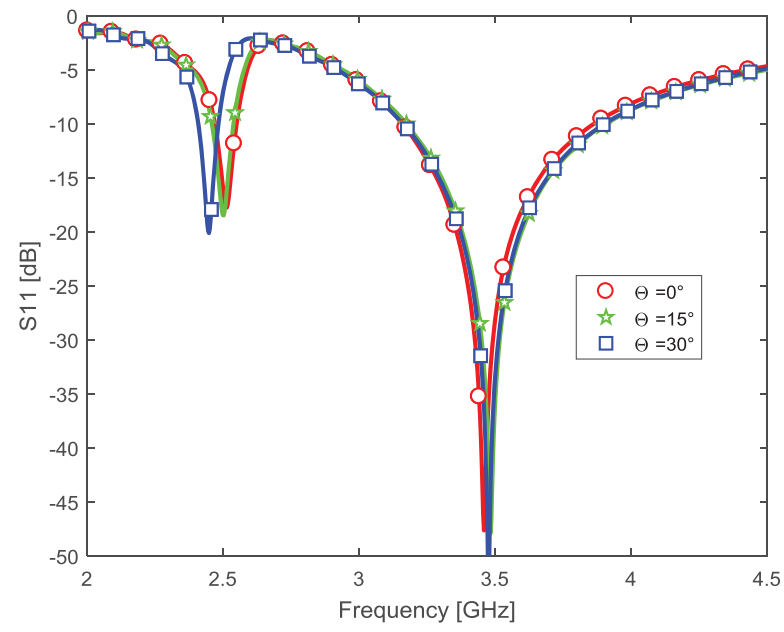

(f)

Figure 5: Return losses of the proposed antenna for different values of (a) S1, (b) Wf, (c) t, (d) d,(e) Lg and, (f) $\theta$. 


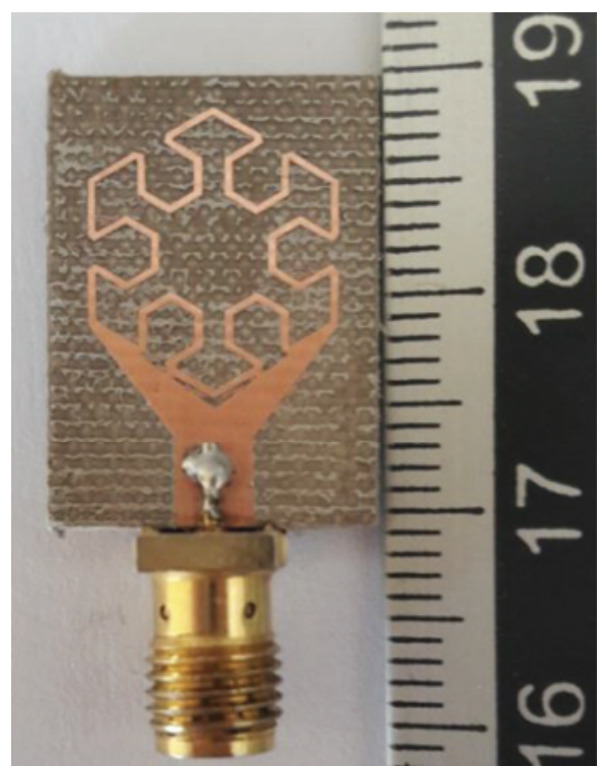

(a)

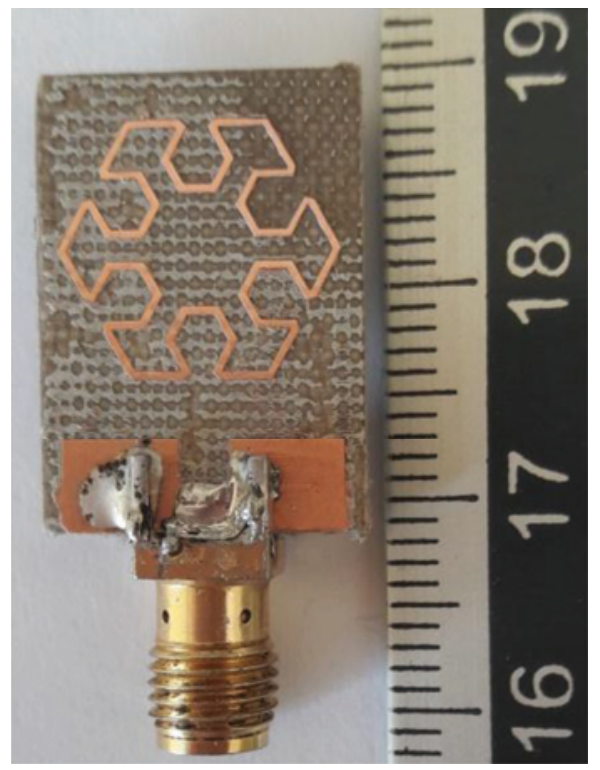

(b)

Figure 6: Photograph of the fabricated dual-band antenna prototype.

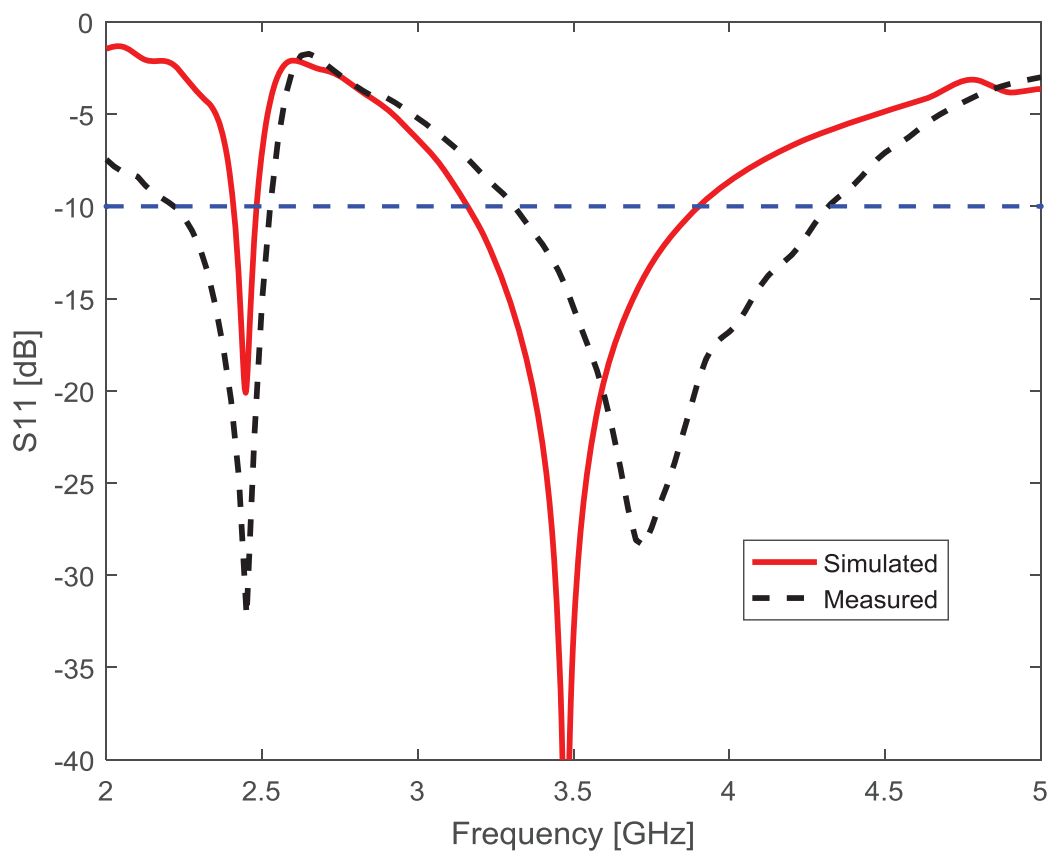

Figure 7: Simulated and measured return losses of the proposed antenna.

The radiation efficiency $\eta$ of the proposed antenna was measured using the Wheeler cap method $[17,18]$ (see Figure 8):

$$
\eta=\frac{\operatorname{Real}\left\{Z_{\text {in }}\right\}-\operatorname{Real}\left\{Z_{w c}\right\}}{\operatorname{Real}\left\{Z_{\text {in }}\right\}}
$$

where $Z_{\text {in }}$ is the input impedance on the antenna and $Z_{w c}$ is the input impedance of the proposed antenna enclosed in a metallic sphere. At $2.45 \mathrm{GHz}$ and $3.5 \mathrm{GHz}$, the measured radiation efficiencies are $91 \%$ and $97 \%$, respectively. Therefore, these good radiation efficiencies at both operating bands make the proposed antenna suitable for the intended application. 

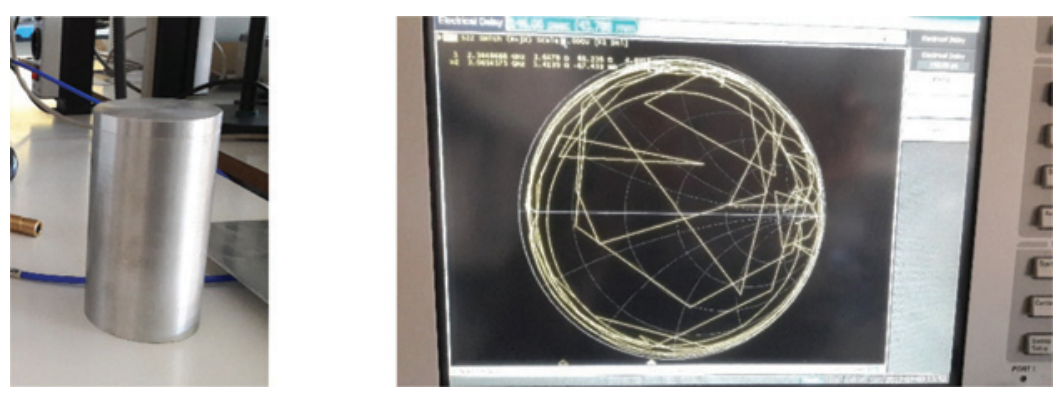

Figure 8: Cup used to measure the efficiency and measured input impedance of the enclosed antenna.

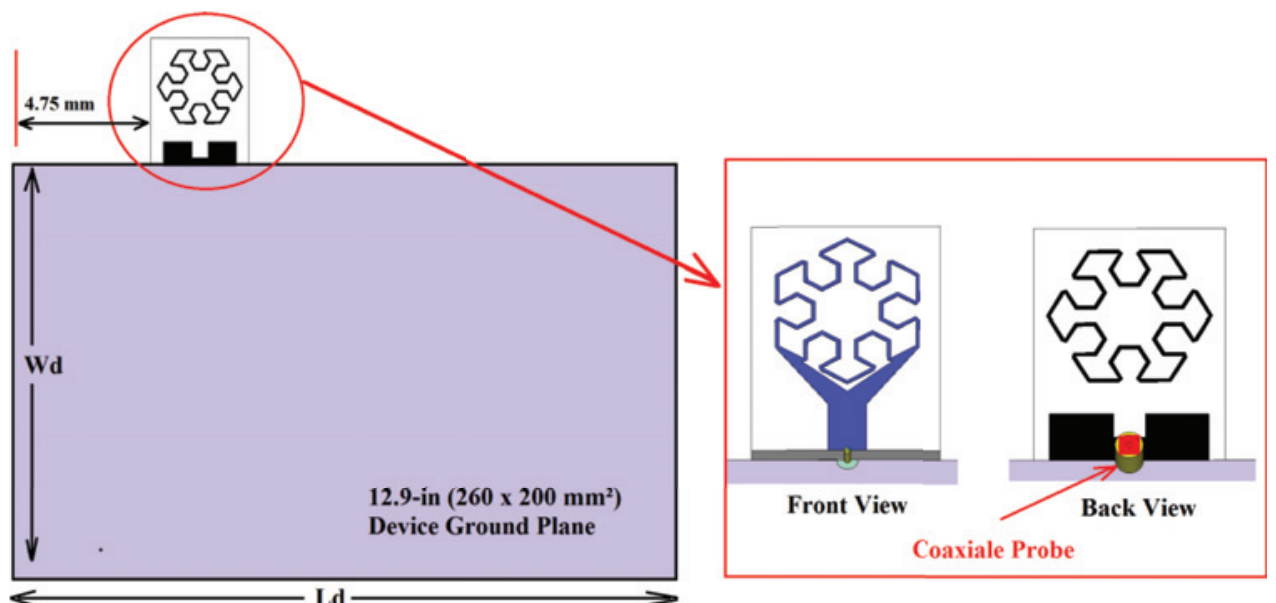

(a)

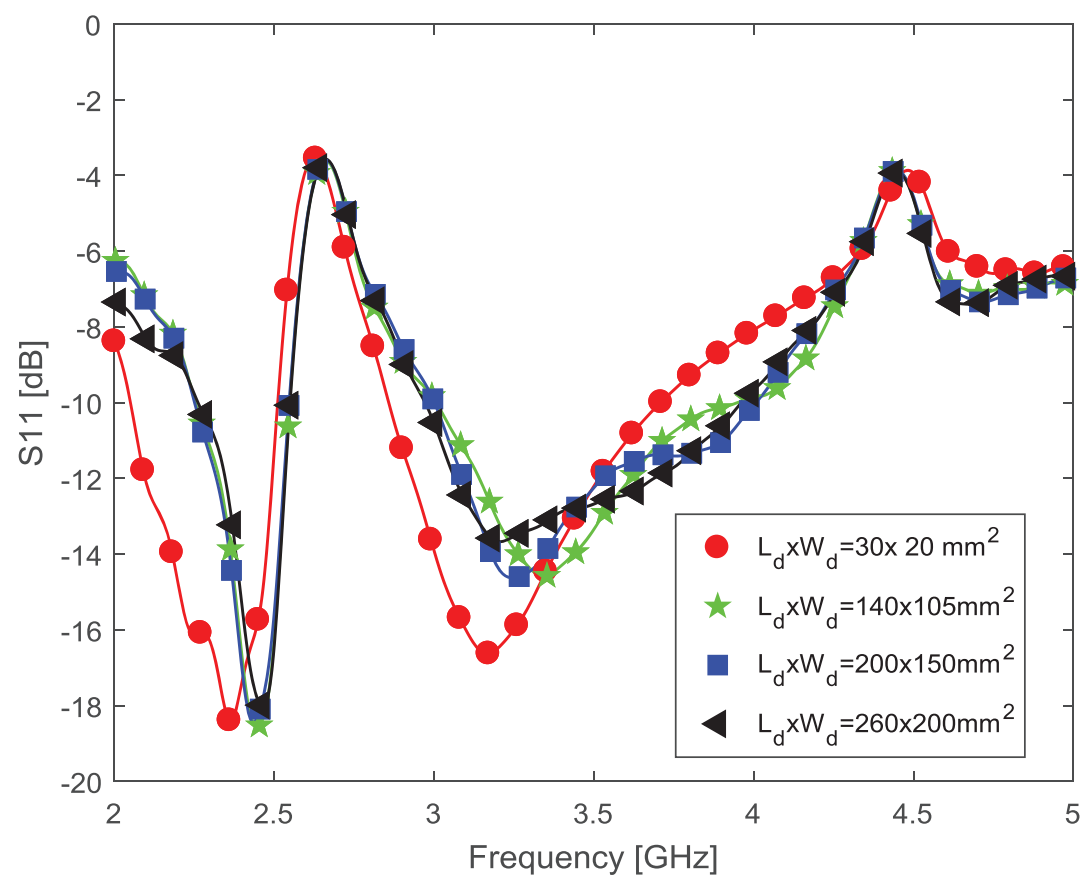

(b)

Figure 9: (a) Antenna attached to system ground plane of 12.9-in laptop computer and (b) Simulated return losses of the proposed antenna for different ground plane sizes. 
For practical applications, laptop and other portable devices, the proposed antenna was mounted on the side of a SGP of laptop computer as shown in Figure 9(a). The reflection coefficient of the proposed antenna was simulated for different SGP sizes (7.5-, 9.7-, and 12.9-in) of laptop computer. The simulated return losses are illustrated in Figure 9(b). It is clear from the results that the antenna resonances are not affected by the SGP size even when it is reduced to $30 \times 20 \mathrm{~mm}^{2}$. Figure 10 shows the fabricated prototype of the proposed antenna, placed at $4.75 \mathrm{~mm}$ from the left corner of a copper SGP (260 $\mathrm{mm} \times 200 \mathrm{~mm}$ ), along with its measured and simulated return losses. It is clearly seen that the simulated and measured results are in good agreement. However, slight difference in measured results can be seen for the second band. Even though, the measured return loss is better than $9 \mathrm{~dB}$ over the frequency band extending from 3 to simulated results are in very good agreement. Moreover, the antenna exhibits an omnidirectional radiation patterns in the $\mathrm{H}$-plane and monopole-like radiation patterns in the E-plane at both resonant frequencies. Accordingly, this confirms that the proposed antenna is well-suited for wireless communication applications.

The slight difference between measured and simulated radiation patterns are attributed to perturbation in the radiation pattern introduced by the positioner during the measurement process.

A comparison between the proposed antenna and other dual-band antennas reported in the literature is presented in Table 2. By comparing the reported antennas footprints, it is clearly seen that the proposed antenna has the smallest one. It can be concluded that the proposed antenna achieves significant size reduction. Moreover, In terms of impedance matching performance,

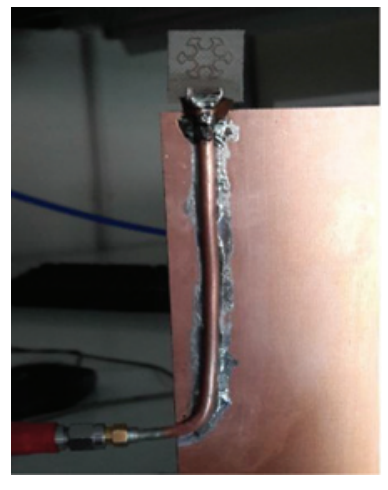

(a)

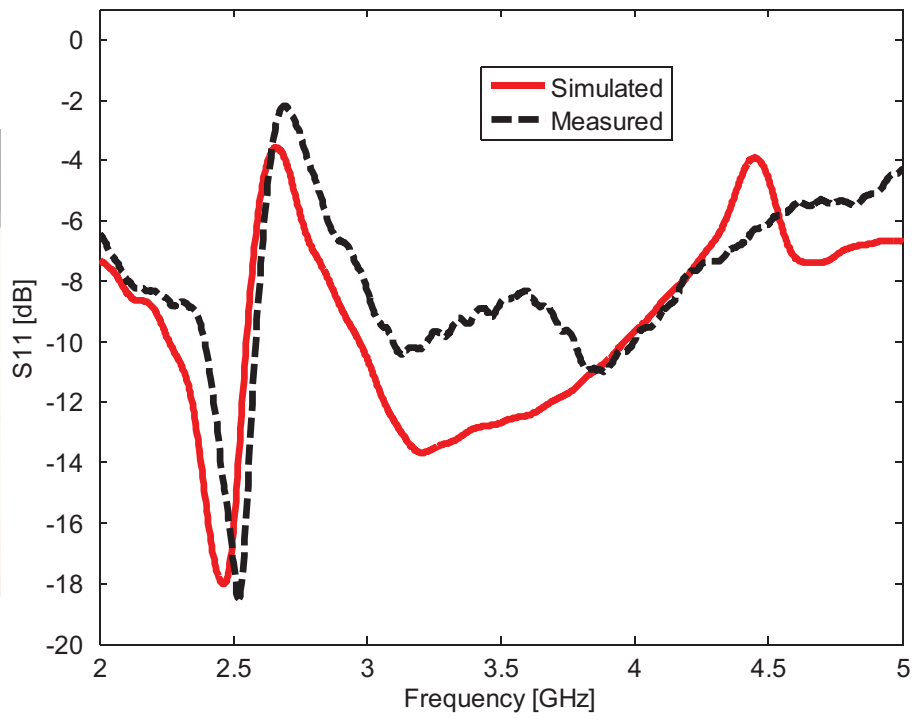

(b)

Figure 10: (a) Fabricated antenna attached to system ground plane of 12.9-in laptop computer and (b) Its simulated and measured return losses.

4.1 GHz. This deviation between the measured and simulated results is mainly attributed to the fabrication errors. Consequently, it can be concluded that the proposed antenna is a good candidate to be integrated into different standard of laptop computers.

The proposed antenna radiation patterns were also measured in an anechoic chamber available in UPC. The normalized measured and simulated radiation patterns containing co-polarization $\mathrm{E}_{\theta}$ and cross-polarization $\mathrm{E}_{\varphi}$ in the H-plane ( $\mathrm{x}-\mathrm{z}$ plane) and E-plane (y-z plane) are shown in Figure 11. It is clear that the measured and the proposed antenna outperforms almost all the reported antennas.

\section{Conclusion}

A new compact dual-band antenna for WLAN/WiMAX applications has been designed, fabricated and tested. The proposed antenna, based on a combination of two coupled fractal rings along with Y-shaped feeding line, has been mounted on SGP of a laptop computer in order 


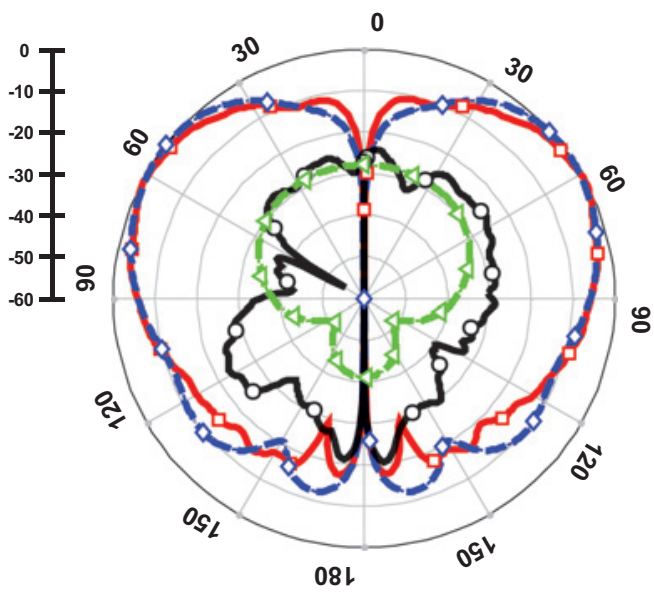

(a1) $\mathrm{f}=2.45 \mathrm{GHz}$

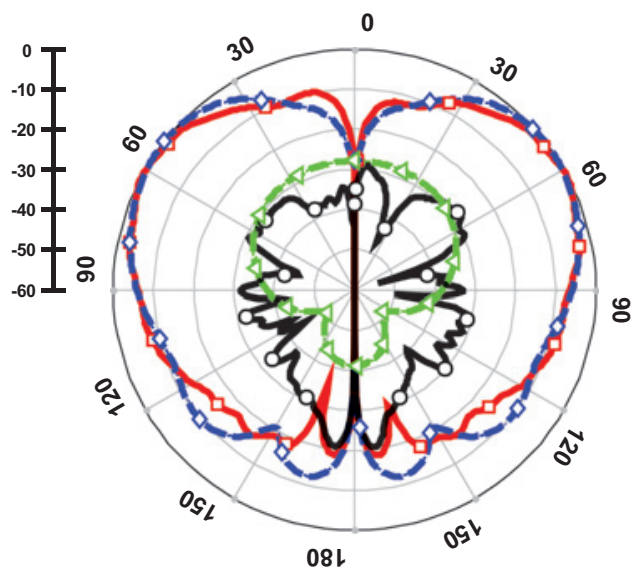

(b1) $\mathrm{f}=2.45 \mathrm{GHz}$

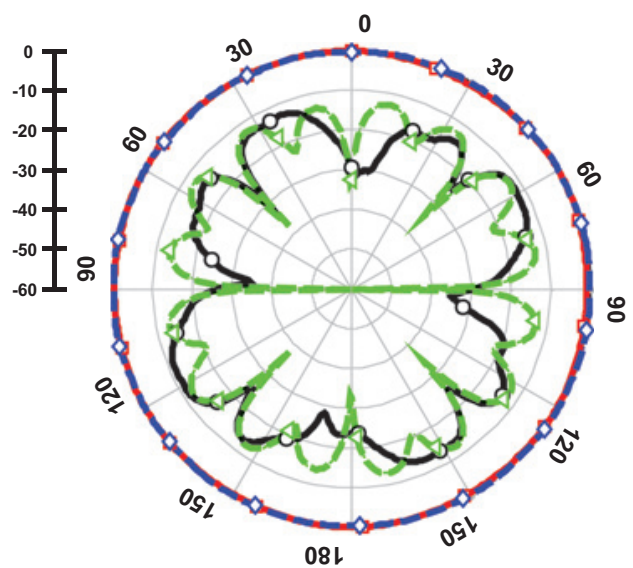

(c1) $\mathrm{f}=2.45 \mathrm{GHz}$

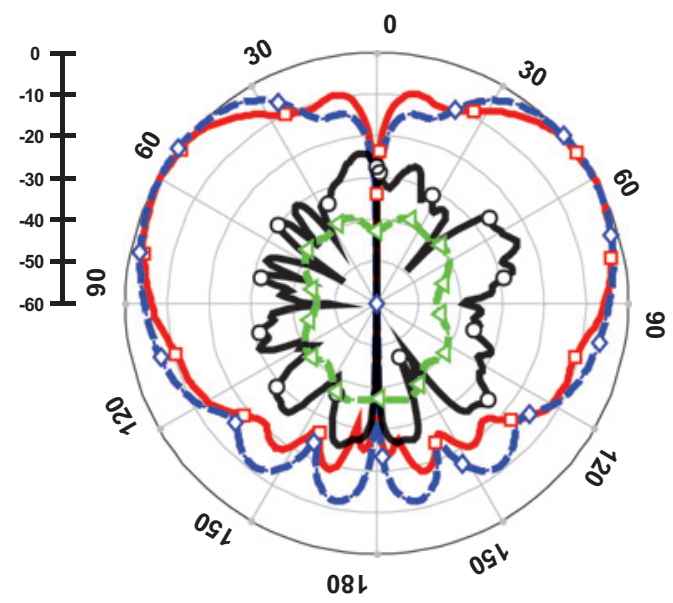

(a2) $\mathrm{f}=3.5 \mathrm{GHz}$

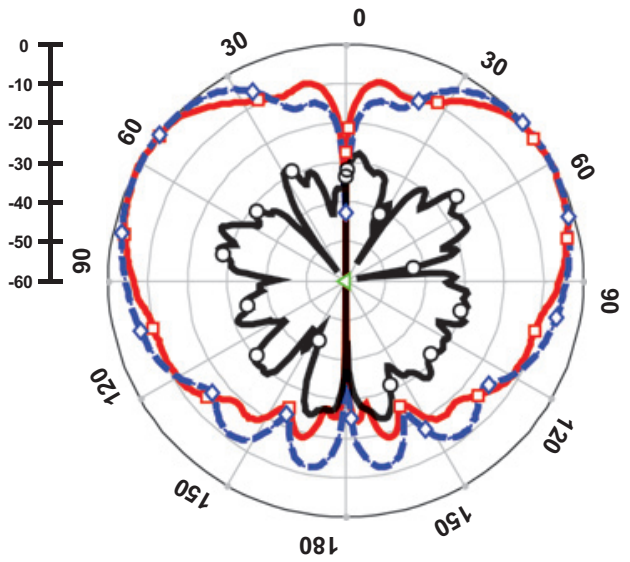

(b2) $\mathrm{f}=3.5 \mathrm{GHz}$

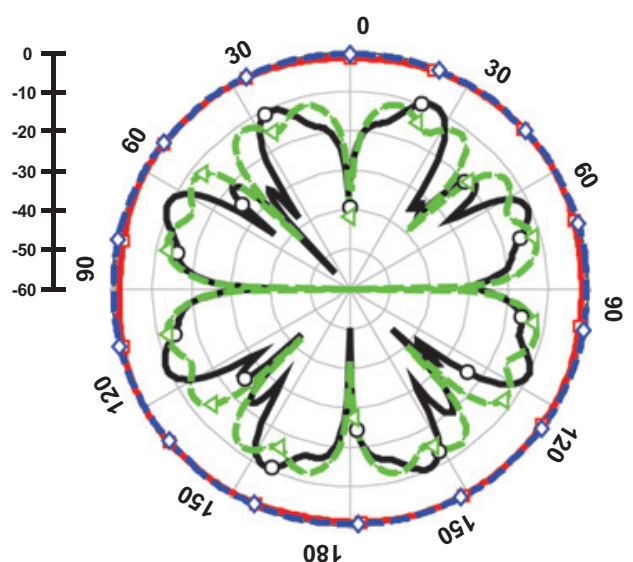

(c2) $\mathrm{f}=3.5 \mathrm{GHz}$

$-\square-E_{\theta}$ Measured $-\prec-E_{\theta}$ Simulated $\multimap-E_{\phi}$ Measured $-\prec--E_{\phi}$ Simulated

Figure 11: Radiation patterns of the proposed antenna at different frequencies 2.45 and $3.5 \mathrm{GHz}$ for (a) $\varphi=0^{\circ}$ plane, (b) $\varphi=90^{\circ}$ plane and (c) $\theta=90^{\circ}$ plane. 
Table 2: Comparison between the proposed antenna and other dualband antennas.

\begin{tabular}{|c|c|c|c|c|}
\hline Reference & $\begin{array}{r}\text { Frequency } \\
(\mathrm{GHz})\end{array}$ & $\begin{array}{r}\text { Frequency } \\
\text { ratio }\end{array}$ & $\begin{array}{r}\text { Antenna } \\
\text { Footprint }\end{array}$ & $\begin{array}{r}\text { Bandwidth } \\
(\%)\end{array}$ \\
\hline [16] & $3.5 / 5.5$ & 1.57 & $0.068 \lambda_{0}{ }^{2}$ & $\begin{array}{l}20.2 \% \\
24.8 \%\end{array}$ \\
\hline [19] & $1.9 / 2.5$ & 1.32 & $0.062 \lambda_{0}^{2}$ & $\begin{array}{l}5.8 \% \\
4.0 \%\end{array}$ \\
\hline [20] & $2.4 / 3.5$ & 1.46 & $0.026 \lambda_{0}^{2}$ & $\begin{array}{l}5.7 \% \\
6.3 \%\end{array}$ \\
\hline [21] & $2.4 / 5.2$ & 2.17 & $0.102 \lambda_{0}^{2}$ & $\begin{array}{r}10.3 \% \\
19 \%\end{array}$ \\
\hline [22] & $2.4 / 3.5$ & 1.46 & $0.024 \lambda_{0}^{2}$ & $\begin{array}{r}123.5 \% \\
24 \%\end{array}$ \\
\hline [23] & $\begin{array}{l}2.45 \\
3.50 \\
5.35\end{array}$ & - & $0.113 \lambda_{0}^{2}$ & $\begin{array}{l}2.0 \% \\
2.0 \% \\
5.7 \%\end{array}$ \\
\hline [24] & $\begin{array}{r}2.5 \\
3.47 \\
5.75\end{array}$ & - & $0.022 \lambda_{0}^{2}$ & $\begin{array}{r}6.45 \% \\
3.03 \% \\
5.9 \%\end{array}$ \\
\hline This work & $\begin{array}{l}2.4 \\
3.5\end{array}$ & 1.46 & $0.016 \lambda_{0}^{2}$ & $\begin{array}{l}12.6 \% \\
26.8 \%\end{array}$ \\
\hline
\end{tabular}

to investigate its performance. The measured results have shown a satisfactory agreement with the simulated ones. The developed antenna with compact size of $18.9 \times 13 \mathrm{~mm}^{2}$ has shown dual-band operation (it covers widely the bands allocated to $2.4 \mathrm{GHz}$ WLAN and $3.5 \mathrm{GHz}$ WiMAX) and good radiation patterns in both $\mathrm{E}$ and $\mathrm{H}-$ planes. Thus, these interesting characteristics make the proposed antenna suitable for the intended application.

Acknowledgements: The authors express their thanks to Professor Jordi Romeu from CommSensLab, Universitat Politècnica de Catalunya, Barcelona, Spain, and to Mrs F. Mouhouche, University M'Hamed BOUGARA of Boumerdes, Institute of Electrical and Electronic Engineering, Signals and Systems Laboratory, for providing support and assistance to perform simulations by using software and, for helping during the fabrication and measurement of the proposed antenna prototype.

\section{References}

[1] K. Fertas, H. Kimouche, M. Challal, H. Aksas, R. Aksas, and A. Azrar, "Design and optimization of a CPW-fed tri-band patch antenna using genetic algorithms," Appl. Comput. Electromagnet. Soc. J., vol. 30, pp. 754-759, 2015.

[2] K. Fertas, H. Kimouche, M. Challal, H. Aksas, and R. Aksas, "An optimized shaped antenna for multiband applications using Genetic Algorithm," in 2015 4th International Conference on Electrical Engineering (ICEE), pp. 1-4.
[3] X.-W. Dai, L. Li, Z.-Y. Wang, and C.-H. Liang, "High isolation and compact MIMO antenna system with defected shorting wall," Int. J. Microw. Wirel. Technol., vol. 7, pp. 167-172, 2015.

[4] J. A. Tirado-Méndez, H. Jardón-Aguilar, F. Iturbide-Sánchez, I. Garcia-Ruiz, V. Molina-Lopez, and R. Acevo-Herrera, "A proposed defected microstrip structure (DMS) behavior for reducing rectangular patch antenna size," Microw. Opt. Technol. Lett., vol. 43, pp. 481-484, 2004.

[5] K. A. Ansal and T. Shanmuganantham, "Compact ACS-fed antenna with DGS and DMS for WiMAX/WLAN applications," Int. J. Microw. Wirel. Technol., vol. 8, pp. 1095-1100, 2016.

[6] A. Gupta, H. D. Joshi, and R. Khanna, "An X-shaped fractal antenna with DGS for multiband applications," Int. J. Microw. Wirel. Technol., vol. 9, pp. 1075-1083, 2017.

[7] K. Djafri, M. Challal, R. Aksas, M. Dehmas, and F. Mouhouche, "A Compact ACS-Fed Tri-band Microstrip Monopole Antenna for WLAN/WiMAX Applications “ presented at the International Conference on Electronics and New Technologies, M'sila, ALGERIA, 2017.

[8] H. Wang, L.-M. Si, and X. Lv, "A compact dual-band patch antenna using metamaterial structures," in Applied Computational Electromagnetics Society Symposium (ACES) International, 2017, 2017, pp. 1-2.

[9] S. Singhal, T. Goel, and A. K. Singh, "Hexagonal tree shaped ultra-Wideband fractal antenna," Int. J. Electron. Lett., vol. 5, pp. 335-348, 2017.

[10] Y. K. Choukiker, S. K. Sharma, and S. K. Behera, "Hybrid fractal shape planar monopole antenna covering multiband wireless communications with MIMO implementation for handheld mobile devices," IEEE Trans. Antennas Propag., vol. 62, pp. 1483-1488, 2014.

[11] S. Singhal, T. Goel, and A. Kumar Singh, "Inner tapered treeshaped fractal antenna for UWB applications," Microw. Opt. Technol. Lett., vol. 57, pp. 559-567, 2015.

[12] K. Djafri, M. Challal, R. Aksas, F. Mouhouche, and M. Dehmas, "Miniaturized Concentric Fractal Rings Microstrip Patch Antenna for Wireless Applications " presented at the International Conference on Automatic control, Telecommunication and Signals Annaba - Algeria, 2017.

[13] G. Varamini, A. Keshtkar, and M. Naser-Moghadasi, "Compact and miniaturized microstrip antenna based on fractal and metamaterial loads with reconfigurable qualification," Int. J. Electron. Commun. (AEÜ), vol. 83, pp. 213-221, 2018.

[14] M. N. Iqbal and S. F. Jilani, "An ultrawideband monopole fractal antenna with coplanar waveguide feed," Int. J. Antennas Propag., vol. 2014,pp.1-7, 2014.

[15] V. Radonić, K. Palmer, G. Stojanović, and V. Crnojević-Bengin, "Flexible Sierpinski carpet fractal antenna on a Hilbert slot patterned ground," Int. J. Antennas Propag., vol. 2012,pp.1-7, 2012.

[16] D. K. Naji, "Compact design of dual-band fractal ring antenna for WiMAX and WLAN applications," Int. J. Electromagn. Applications, vol. 6, pp. 42-50, 2016.

[17] D. Agahi and W. Domino, "Efficiency measurements of portable-handset antennas using the wheeler cap," App. Microw. Wirel., vol. 12, pp. 34-43, 2000.

[18] H. Choo, R. Rogers, and H. Ling, "On the Wheeler cap measurement of the efficiency of microstrip antennas," IEEE Trans. Antennas Propag., vol. 53, pp. 2328-2332, 2005.

[19] T. Yue, Z. H. Jiang, A. H. Panaretos, and D. H. Werner, "A Compact Dual-Band Antenna Enabled by a Complementary 
Split-Ring Resonator-Loaded Metasurface," IEEE Trans.

Antennas Propag., vol. 65, pp. 6878-6888, 2017.

[20] J. Malik, A. Patnaik, and M. Kartikeyan, "A compact dual-band antenna with omnidirectional radiation pattern," IEEE Antennas Wirel. Propag. Lett., vol. 14, pp. 503-506, 2015.

[21] J.-H. Lu and H.-S. Huang, "Planar compact dual-band monopole antenna with circular polarization for WLAN applications," Int. J. Microw. Wirel. Technol., vol. 8, pp. 81-87, 2016.
[22] P. V. Naidu, "Printed V-shape ACS-fed compact dual band antenna for bluetooth, LTE and WLAN/WiMAX applications," Microsyst. Technol., vol. 23, pp. 1005-1015, 2017.

[23] A. Bekasiewicz and S. Koziel, "Miniaturized uniplanar tripleband slot dipole antenna with folded radiator," Microw. Opt. Technol. Lett., vol. 60, pp. 386-389, 2018.

[24] T. Ali and R. C. Biradar, "A triple-band highly miniaturized antenna for WiMAX/WLAN applications," Microw. Opt. Technol. Lett., vol. 60, pp. 466-471, 2018. 